\title{
Para descolonizar el hábitat rural. Un análisis de la matriz colonial de las políticas públicas habitacionales en Córdoba (Argentina)
}

To Decolonize Rural Habitat. An Analysis of the Colonial Matrix of Public Housing Policies in Córdoba (Argentina)

Para descolonizar o hábitat rural. Uma análise

da matriz colonial das politicas públicas

habitacionais em Córdoba (Argentina)

Noelia Cejas

Recibido: $1^{\circ}$ de agosto de 2019

Aprobado: 21 de enero de 2020

Doi: https://doi.org/10.12804/revistas.urosario.edu.co/territorios/a.8150

Para citar este artículo:

Cejas, N. (2020). Para descolonizar el hábitat rural. Un análisis de la matriz colonial de las políticas públicas habitacionales en Córdoba (Argentina). Territorios, (43), 1-22. https://doi.org/10.12804/revistas. urosario.edu.co/territorios/a.8150

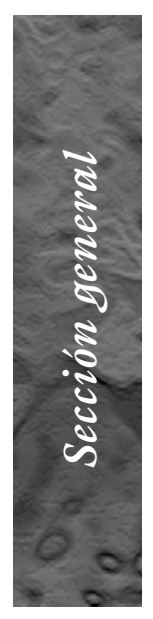

* Investigadora asistente en el Centro Experimental de Vivienda Económica (CEVE), unidad ejecutora del Consejo Nacional de Investigaciones Cientificas y Técnicas de la Nación (Conicet). Correo electrónico: noelia_cejas@ outlook.com. ORCID: https://orcid.org/00000001-9793-3031 
Palabras clave

Decolonial; colonialidad del poder; politica babitacional; rural; campesino.

Keywords

Decolonial; coloniality of power; housing policy; rural; peasant.

Palavras-chave

Decolonial; colonialidade do poder; politica habitacional; rural; camponês.

\section{tersitarias 43}

\section{RESUMEN}

El artículo recupera las reflexiones de la perspectiva decolonial, especialmente conceptualizaciones que Rita Segato (2013) realiza en torno a la noción de "colonialidad del poder", concepto originalmente acuñado por el sociólogo peruano Aníbal Quijano. Me propongo abordar políticas habitacionales orientadas a las comunidades rurales campesinas del noroeste provincial, promovidas por el Gobierno de la Provincia de Córdoba (Argentina). Concretamente, se analizará el Plan de Sustitución de Viviendas Precarias y Erradicación del Mal de Chagas, el cual forma parte del Programa de Desarrollo del Noroeste Cordobés (PDNC). Para su análisis, me valdré de los ejes argumentales que Segato define para organizar su crítica al orden colonial. El supuesto que guía el trabajo consiste en señalar - críticamente- la matriz colonial que subyace en las intervenciones territoriales en comunidades rurales campesinas, produciendo efectos de afirmación de la exclusión por medio de políticas asistencialistas y pretendidamente compensatorias.

\section{ABSTRACT}

The article recovers the reflections from the decolonial perspective, especially conceptualizations that Rita Segato (2013) makes around the notion of "coloniality of power", a concept originally coined by the Peruvian sociologist Aníbal Quijano. I intend to address housing policies aimed at rural peasant communities in the provincial northwest, promoted by the Government of the Province of Córdoba (Argentina). Specifically, will analyze the Plan de Sustitución de Viviendas Precarias y Erradicación del Mal de Chagas (Plan for the Substitution of Precarious Housing and the Eradication of Chagas Disease), which is part of the Programa de Desarrollo del Noroeste Cordobés (Northwest Cordovan Development Program). For this analysis, I will use the argumental axes that Segato defines to organize his critique of the colonial order. The assumption that guides the work consists in pointing out — critically — the colonial matrix that underlies the territorial interventions in rural communities, producing effects of affirmation of exclusion through welfare and purportedly compensatory policies.

\section{RESUMO}

O artigo recupera as reflexões da perspectiva decolonial, especialmente conceptualizações que Rita Segato (2013) realiza em torno à noção de "colonialidade do poder", conceito originalmente inventado pelo sociólogo peruano Aníbal Quijano. Me proponho abordar políticas habitacionais orientadas às comunidades rurais camponesas do nordeste provincial, promovidas pelo Governo da Província de Córdoba (Argentina). Concretamente, se analisará o Plano de Substituição de Moradias Precárias e Erradicação da Doença de Chagas, o qual forma parte do Programa de Desenvolvimento do Nordeste de Córdoba (PDNC). Para sua análise, basear-me-ei nos eixos argumentais que Segato define para organizar sua crítica à ordem colonial. O suposto que guia o trabalho consiste em assinalar — criticamente - a matriz colonial que subjaz nas intervenções territoriais em comunidades rurais camponesas, produzindo efeitos de afirmação da exclusão por meio de políticas assistencialistas e pretensamente compensatórias. 


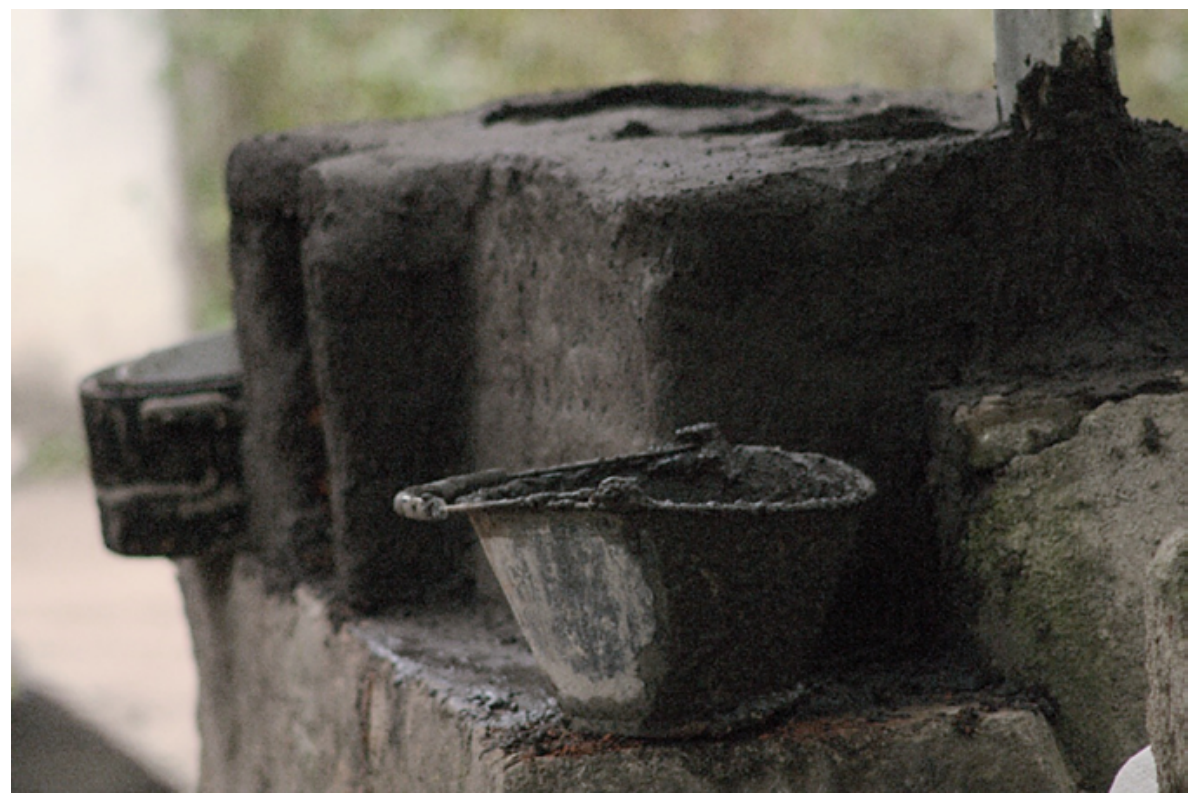

Fuente: trabajo de campo GIEH (2018).

\section{Introducción}

La falta de acceso al hábitat digno es un problema estructural, persistente y extendido en toda Latinoamérica. En Argentina, el Centro de Estudios Legales y Sociales (CELS, 2017) observa que esta problemática afecta principalmente a sectores urbanos populares, a amplios sectores de clase media, a campesinos y a comunidades indígenas. En el medio rural, la problemática de falta de acceso al hábitat digno por parte de campesinos se inscribe en relación con otras expresiones en el territorio: concentración de la tierra, expansión del modelo agroindustrial y modos de producción altamente intensivos que amenazan los modos de vida campesinos. La exclusión de estas comunidades está asociada a la presencia de dificultades para realizar actividades económicas tradicionales; a veces esas dificultades remiten a daños ambientales irreversibles, lo cual produce el desplazamiento de familias rurales hacia periferias urbanas (CELS, 2017, p. 8).

Sin lugar a duda, el ámbito urbano es el territorio donde el Estado, de manera prioritaria, se aboca al abordaje de las problemáticas de falta de acceso al hábitat territarias 43 
${ }^{1}$ Los proyectos a los que se hace referencia son: "Desarrollo tecnológico situado en el hábitat rural. Alternativas integrales para el abordaje de sus funciones residencial, productiva $y$ de socialización”, bajo la dirección de Adrián Carbonetti. Convocatoria PIODO 2018-Mincyt Córdoba. Resolución Provincial 69 de 2018; $y$ "Transferencia de tecnologias a nivel jurídico, constructivo y económico para el fortalecimiento de la producción de pequeña escala en la Cooperativa Gallo Rojo”, bajo la dirección de Noelia Cejas. Convocatoria $i+T e c$ Social 2018. Resolución Provincial 128 de 2018 del Ministerio de Ciencia y Tecnología de Córdoba.

\section{territarios 43}

digno. En parte esto puede explicarse por el alto grado de concentración de población urbana respecto de la rural en Argentina. Los últimos datos censales en este país son del año 2010 y señalan una concentración del $91 \%$ de población en ciudades. Complementariamente, otras fuentes indican la creciente concentración de población empobrecida en el medio rural. La Organización de las Naciones Unidas para la Alimentación y la Agricultura (FAO) señala en su informe Panorama de la pobreza rural en América Latina y el Caribe 2018 datos estadísticos preocupantes: los porcentajes de población en situación de pobreza rural y de pobreza extrema rural en la región alcanzaron el $48,6 \%$ y el $22,5 \%$, respectivamente.

Los elementos señalados hasta aquí permiten abrir un espacio de discusión respecto de aquello que es posible pensar sobre el hábitat rural-campesino en sus concurrencias para ser concebido como hábitat digno. Algunos aspectos que configuran el escenario por abordar pueden ser expresados en las siguientes preguntas: ¿qué implicancias trae el actual modelo de desarrollo?, ¡ es el modelo agroindustrial neoliberal compatible con las prácticas productivas agrícolas campesinas?, ¿las políticas públicas habitacionales reconocen, fortalecen o siquiera permiten objetivar las formas de habitar campesinas?, ¿’es el reductivismo a la escala habitacional-material una manera de reafirmar la exclusión? Los interrogantes son provocadores y están especialmente dirigidos a los lineamientos que componen las políticas habitacionales en el medio rural cordobés (provincia de Córdoba, Argentina).

El Programa de Desarrollo del Noroeste Cordobés (PDNC) tiene por objetivo promover el desarrollo socioproductivo de la región norte y oeste de la provincia de Córdoba, mediante estrategias de intervención que transformen e, idealmente, mejoren la calidad de vida de sus habitantes. Para ello, abarca un territorio de 50000 kilómetros cuadrados, que congrega 135 parajes de diez departamentos del noroeste provincial, donde habitan más de 230000 habitantes (Sesma \& Martínez Coenda, 2019). En el marco de estas acciones se encuentra el Plan de Sustitución de Viviendas Precarias y Erradicación del Mal de Chagas (PSVPEMC). Los alcances de esta política pública suponen el abordaje de un vasto territorio provincial, tal como puede observarse en la figura 1. No obstante ello, vale señalar que las observaciones realizadas en este trabajo se asientan en comunidades campesinas de dos de estos departamentos: Tulumba y San Alberto.

En este sentido se hacen dos observaciones de orden metodológico. En primer lugar, vale indicar que el trabajo de investigación en estos territorios se sostiene mediante dos proyectos financiados por el Ministerio de Ciencia y Tecnología de la provincia de Córdoba, ${ }^{1}$ en ejecución desde 2018. La incipiente indagación supone el acercamiento a dos comunidades/ organizaciones campesinas alcanzadas por 
Figura 1. Mapa de la provincia de Córdoba (Argentina)

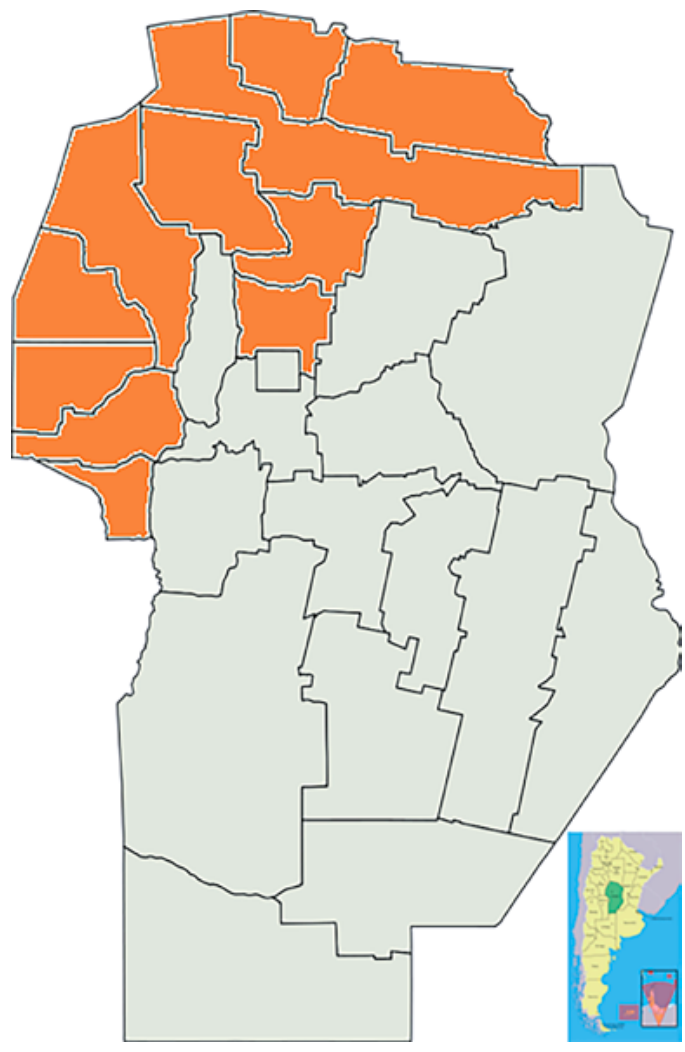

En color se destacan los departamentos alcanzados por el PDNC: Pocho, Minas, Cruz del Eje, San Alberto, San Javier, Ischilín, Totoral, Sobremonte, Río Seco, Tulumba y Colón.

Fuente: mapa original de Wikimedia

Commons, editado por la autora.

el PDNC, residentes en los departamentos mencionados anteriormente. Los alcances de la investigación no permiten efectuar aseveraciones de corte general, aunque permiten acercarnos de manera cualitativa a diversas formas de experimentar los efectos de este programa, concretamente en lo que remite al plan de sustitución de viviendas. El alcance de este trabajo es entonces apenas exploratorio, de diseño cualitativo y perspectiva constructivista, basada en el enfoque decolonial.

En segundo lugar, continuando con las observaciones metodológicas, es preciso apuntar que no existe disponibilidad pública de los fundamentos y objetivos ni del programa ni del plan analizados, por lo cual el análisis se asienta en documentos públicos fragmentarios y dispersos (como leyes, reglamentos, notas de prensa y publicaciones en sitios web oficiales del gobierno provincial), además de artículos en la prensa local, como así también en trabajos publicados por miembros del equipo de investigación del que la autora forma parte, que presentan de manera ordenada los contenidos de aquellos documentos. ${ }^{2}$

A modo introductorio, vale decir que existe un vínculo estrecho entre aspectos que constituyen lo que, siguiendo a Leguizamón Sarmiento (2012), podríamos nombrar como la forma de habitar campesina, analíticamente distinguibles como funcionalidades residenciales, productivas y de sociabilización, que se expresan en el territorio, en el espacio, y que pugnan por sostenerse. Así, esta noción excede su versión consabida material-instrumental como espacio físico (vivienda) y en su lugar supone un ámbito en donde se presentan un conjunto de dinámicas e interacciones entre elementos de distintos campos o dimensiones (tales como el económico,
2 Se destaca el trabajo realizado por Sesma y Martínez Coenda (2019), donde se plantea, desde la estrategia metodológica de análisis del discurso, la indagación sobre un vasto corpus, al cual también se accedió para este trabajo: la Ley Provincial 9601, que declara la emergencia habitacional-sanitaria en la provincia de Córdoba; los informes de gestión del PDNC pertenecientes a los años 2015 y 2018, donde se incluye una recopilación de comunicaciones de prensa oficiales a partir de las cuales se relatan los avances y resultados parciales del programa; el testimonio de una exfuncionaria provincial, encargada de ejecutar el PSVPEMC, recuperado en una ponencia del Congreso de Trabajo Social; el testimonio de dos funcionarios provinciales encargados de ejecutar el PSVPEMC actualmente, entrevistados por las autoras a los fines de ese trabajo; el testimonio de dos militantes de organizaciones campesinas de Córdoba, plasmado en entrevistas realizadas a los fines de ese trabajo; el testimonio de una adjudicataria del PSVPEMC, cuya vivienda de adobe fue sustituida

$\Longrightarrow$

territarias 43 
$\Longleftarrow$

por una de materiales industriales; el testimonio de un adjudicatario del PSVPEMC, cuya vivienda de adobe no fue destruida tras la construcción de la de materiales industriales en su mismo terreno.

\section{tersitarias 43}

el físico-espacial, el cultural, el natural, el social, el político). Todos estos elementos configuran entramados o sistemas que hacen posible la vida humana, el hábitat (Múnera \& Sánchez Mazo, 2012). En este sentido, el hábitat comprende lo relativo al sistema espacial y de recursos de los que se vale un grupo para transitar por su existencia. Esto responde a las necesidades y deseos que el grupo y sus individuos presentan, tras el objetivo de desarrollar su vida productiva-laboral, de organización social y residencial (Mandrini et al., 2018).

Desde esta perspectiva integral del hábitat, me propongo abordar las políticas habitacionales orientadas a las comunidades rurales campesinas del noroeste cordobés, procurando revisar las definiciones con que se impacta en los territorios, para lo cual me valdré de algunos de los ejes argumentales que Rita Segato (2013) define para organizar su crítica al orden colonial. El supuesto que guía el trabajo consiste en resaltar -críticamente- la matriz colonial que subyace en las intervenciones territoriales en comunidades rurales campesinas, produciendo efectos de afirmación de la exclusión por medio de políticas asistencialistas, pretendidamente compensatorias. En la figura 2 podemos observar el tipo de práctica con que el Estado interviene sobre las formas vernáculas de habitar en los territorios rurales vulnerables.

Figura 2. Demolición de una vivienda-rancho

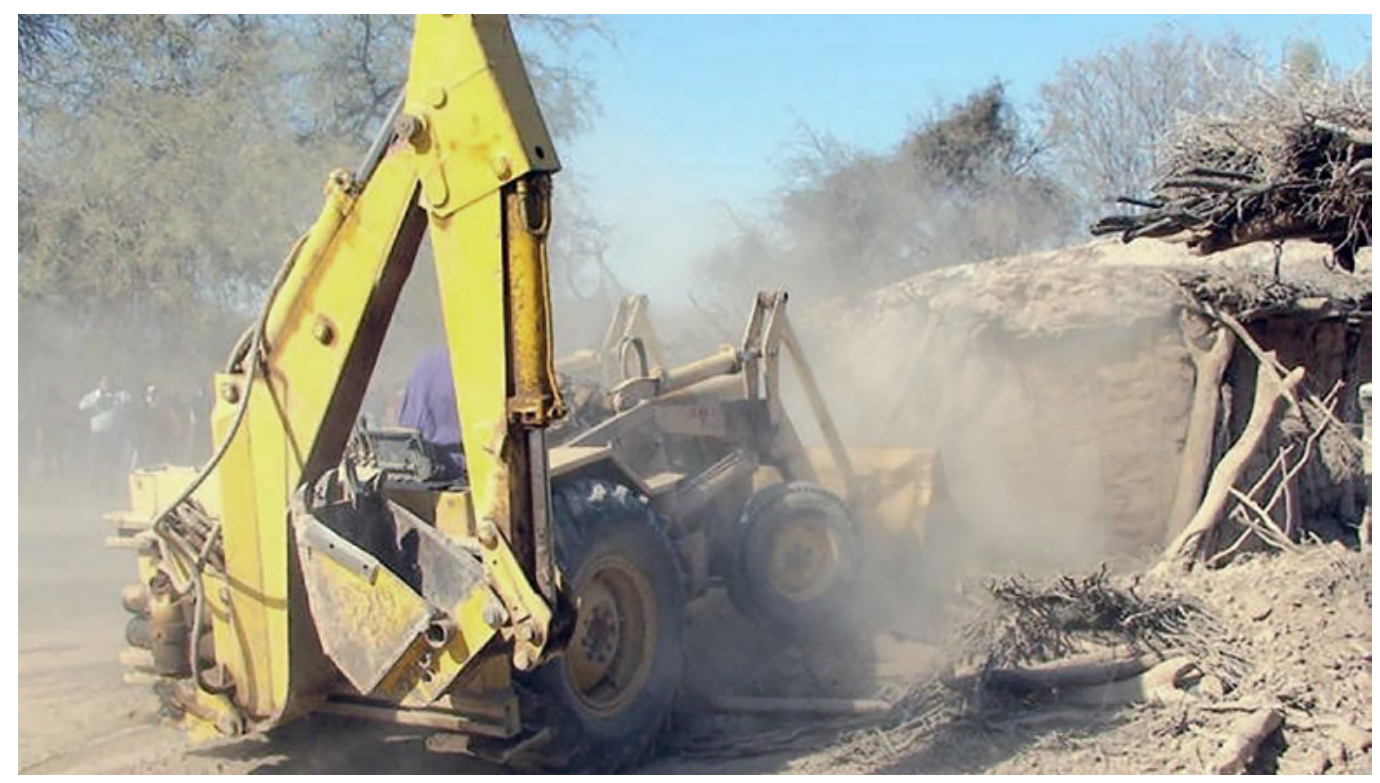

Fuente: diario Día a Día (31 de julio de 2009). 


\section{Breve repaso por la perspectiva de la colonialidad del poder}

Rita Segato (2013) realiza un estudio minucioso de la obra del sociólogo peruano Aníbal Quijano, quien acuñara el concepto de colonialidad del poder. En palabras de la autora, la obra de Quijano constituye uno de los escasos "vocabularios capaces de reconfigurar la historia ante nuestros ojos" (Segato, 2013, p. 35). Junto a la teología de la liberación, la pedagogía del oprimido y la teoría de la marginalidad (superadora de la teoría de la dependencia), la perspectiva de la colonialidad del poder es un claro ejercicio de pensamiento con raíz latinoamericana y de alcance global, constituyendo un esfuerzo que pone en tensión la tradición eurocéntrica de pensamiento y su estructura de poder mundial.

El trabajo de Quijano representa, tal como repasa Segato, un quiebre en las ciencias sociales. La sensibilidad histórica con la cual captura, en términos sociológicos, los efectos de la caída del Muro de Berlín y el fin del orden mundial marcado por la polaridad capitalismo-comunismo abre un espacio de interpretación para la historia política del siglo Xx desde una perspectiva latinoamericana. El lenguaje crítico que el autor construye a partir de esa perspectiva se expresa en la teoría de la colonialidad del poder y da cuenta de la ruptura también en el orden geopolítico epistémico que los hechos históricos imponían. Las antiguas claves conceptuales ya no permitían comprender el nuevo orden mundial, eran (son) necesarios nuevos vocabularios que acompañen las luchas de la sociedad.

La perspectiva propuesta por Quijano constituye un cambio de paradigma relevante que habilita un espacio interpretativo, de investigación y de acción marcados por las emergencias y las urgencias de la época. En 1985, en ocasión de la sesión de cierre de la XIII Asamblea General Ordinaria del Clacso, Quijano ya señalaba la necesidad de sacudir la incertidumbre que generaba la falta de potencial explicativo de las categorías marxistas en las ciencias sociales, acompañando los movimientos de la sociedad latinoamericana en su reciente etapa posdictatorial. El título de aquel trabajo sigue siendo provocativo: "Las ideas son cárceles de larga duración, pero no es indispensable que permanezcamos siempre en esas cárceles" (Quijano, 1985). Volveré sobre esta idea.

Segato, siguiendo un trabajo de Quijano publicado en 1990 (Notas sobre los problemas de investigación social en América Latina), va a sostener que la heterogeneidad latinoamericana no puede ser aprehendida por categorías eurocéntricas, ni siquiera por categorías marxistas. Además de repasar la incapacidad de algunas categorías para explicar las complejas formas de relación y modos de existencia en América Latina, manifiesta que se trata de la articulación estructurada de diversas lógicas históricas en torno de una dominante: el capital (Segato, 2013 , p. 40). Algo que Boaventura de 
${ }^{3}$ La triada discurso-poder-perdad, constituida desde la perspectiva de análisis de discurso que aporta Michel Foucault (1999), constituye el dispositivo interpretativo con que Arturo Escobar estudió la formación del discurso sobre el desarrollo. Para Foucault, el discurso y el poder, comprendidos de manera imbricada, funcionan como una tecnología que entrama relaciones sociales. En ese sentido, el discurso permite legitimar perspectivas de mundo, distinguiendo lo verdadero de lo falso, lo central de lo periférico, lo relevante de lo irrelevante. Así, la idea de saber-poder remite a la idea de verdad.

\section{territarias 43}

Sousa Santos, otro referente del proyecto/ giro decolonial, va a proponer abordar desde el pensamiento posabismal, constituyendo una lectura marxista capaz de integrar aquello que esta no puede ver, desde su ceguera moderna/colonial: "Una concepción postabisal del marxismo [...] ha de disponer que hay que luchar por la emancipación de los trabajadores a la vez que por la emancipación de todas las poblaciones descartables del Sur global, que están oprimidas pero no directamente explotadas por el capitalismo global" (De Sousa Santos, 2017, p. 176).

Esa lectura crítica incluso de la bibliografía marxista está en la base de la noción de colonialidad del poder, concepto con el que Quijano señala el proceso de jerarquización de categorías engendradas en el norte, que pretenden captar o, peor aún, constituyen horizontes deseables de desarrollo para realidades exógenas. Al contemplar los modos de existencia plurales, las múltiples historias y proyectos que existen en la historia del mundo, una vez combinados y articulados en un único relato secuencial, se observan juegos de sentido que tachan de atraso o de utópica a experiencias de mundo que de hecho son contemporáneas. Como ejemplo de esto, Segato (2007) va a señalar los ideales comunistas, las propuestas de comunidad solidaria y diversas expresiones de cosmovisiones de pueblos indígenas que ponen en el centro de la vida las relaciones entre humanos y naturaleza, desmarcándose de patrones como el de competitividad, costo-beneficio, acumulación, etc.; no por acaso, constituyen categorías y experiencias de vida activamente construidas como inferiores.

\section{El desarrollo: una idea de larga duración}

Recuperando aquello que Quijano sostiene, considerando que las ideas pueden convertirse en cárceles de larga duración, introduzco los aportes de Arturo Escobar (2007), quien analiza, desde una perspectiva foucaultiana, ${ }^{3}$ el discurso del desarrollo. Reconociendo la importancia de las dinámicas de discurso y poder en la creación de la realidad social, Escobar indaga en los procesos de construcción discursiva que dieron lugar al auge del 'desarrollo' como modo de relación entre Estados Unidos y Europa, por un lado, y Latinoamérica, África y Asia, por el otro.

Los discursos en torno al desarrollo son comprendidos como un régimen de representación, que surge en el marco de una coyuntura histórica, como es la segunda posguerra, y que se afianza junto al modelo neoliberal, especialmente en las últimas décadas del siglo Xx. Escobar va a subrayar que el discurso sobre el desarrollo se mueve a sus anchas, cubriendo prácticamente toda la geografía cultural, económica y política de los llamados países tercermundistas; entre ellos, habla del discurso sobre el desarrollo rural, tema que abordaré en el próximo apartado. 
La perspectiva decolonial indaga en los pliegues ocultos de aquello que es nombrado como 'modernidad'. Existe cierto efecto de exterioridad, de no modernidad, sobre experiencias de mundo que son consideradas atrasadas, incompletas o, en el mejor de los casos, perfectibles. Esta categorización constituye y perpetúa una trama vincular que se vuelve visible bajo la categoría de colonialidad. La modernidad y la colonialidad están estrechamente vinculadas, como la doble cara de un mismo fenómeno. En palabras de Ramón Grosfoguel, la colonialidad "no se deriva de la modernidad ni antecede a ella. La colonialidad y la modernidad constituyen dos lados de una misma moneda" (Grosfoguel, 2006, p. 27). Es decir, la colonialidad es comprendida como un patrón de poder que emergió y sobrevivió al colonialismo y que es inmanente a la modernidad y el discurso en torno al desarrollo y el progreso como uno de los relatos propios del modelo civilizatorio moderno/colonial, en cuyo seno se legitiman instituciones y prácticas que reproducen órdenes de colonialidad.

Tal como menciono en el apartado anterior, una vez que las diferentes formas de experimentar el mundo o, para el caso, las diferentes formas de habitarlo son combinadas y articuladas en un único relato, ordenadas de manera jerárquica y secuencial, se observan juegos de sentido que fácilmente habilitan la categoría de atrasadas para nombrar a algunas de ellas. Interesa detenernos en esta idea, pues esta forma de ordenar y categorizar distintos modos de habitar rápidamente catalogan a la experiencia de hábitat campesino en el ámbito de lo atrasado o, en el mejor de los casos, de lo perfectible, ya sea que se observan las expresiones materiales de su arquitectura o la distribución de sus funcionalidades (productiva, residencial de organización social) en el espacio. Por medio del PDNC y, más especialmente, por medio del PSVPEMC, el Estado provincial estructura su presencia en el territorio desde la idea de desarrollo y define como precarias a las viviendas campesinas que expresan su arquitectura vernácula (principalmente constituida a partir de las materialidades disponibles en el territorio, aunque también incorporan materiales industrializados, reunidos a partir de las técnicas constructivas históricamente aprendidas, como se ilustra en la figura 3). Así mismo, provee una tipología estandarizada (que puede variar en la cantidad de dormitorios, mas no en las definiciones funcionales) para el vasto territorio provincial que abarca.

Es decir, la modernidad puede ser comprendida como un modelo civilizatorio en el que se configura un nosotros moderno (el Estado, en este caso) con facultad de intervenir en territorios, grupos, conocimientos, prácticas, subjetividades, y que procura transformar las condiciones de existencia de un otro no moderno. Ese mecanismo es el que opera como lógica de intervención en, por caso, los territorios rurales campesinos de Córdoba. territarios 43 9 


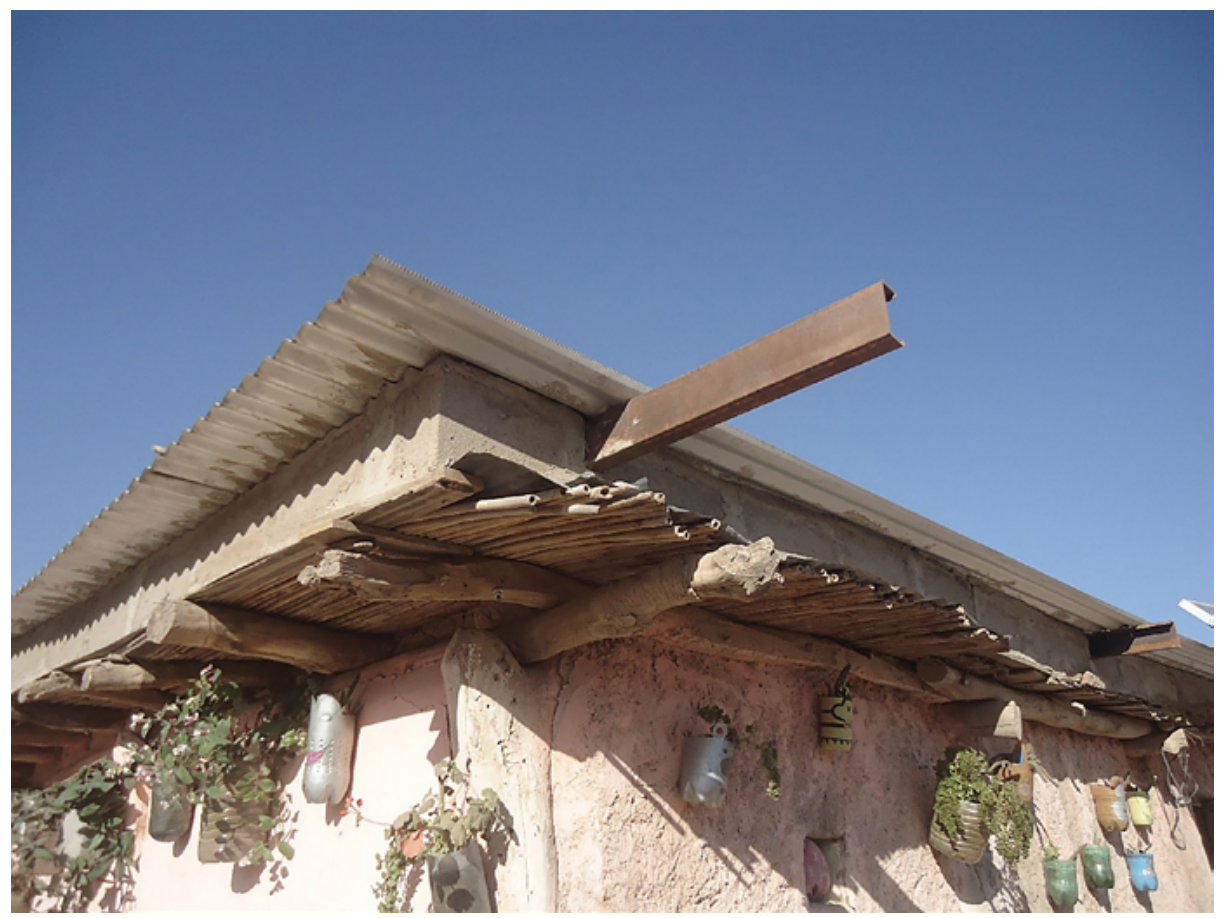

Detalle constructivo en el que se puede observar la diversidad de materiales que dan forma a la arquitectura vernácula: adobes, horcones, enramada, carga de tierra, bloque cementicio, hierro y chapa, entre otros.

Fuente: elaboración de la autora. GIEH (2017).

Profundizando en las prácticas asociadas al discurso del desarrollo, Escobar indica que, a partir de la consolidación del capitalismo, se produce un discurso sobre la pobreza, como modo de cargar negativamente las formas de vida frugales, que genera el escenario para justificar las prácticas intervencionistas y sus correlativos mecanismos de control. En términos de producción de discurso, esto opera por medio de la asignación del atributo de $c a-$ rente como aspecto central de los sectores empobrecidos, para pasar a ser también sectores susceptibles de recibir asistencia (Escobar, 2007, p. 49). Se produce allí un doble movimiento, en el que aquellos sujetos abarcados por la categoría de 'pobres' o 'carentes' (categoría esencialmente articulada desde las condiciones materiales y económicas de existencia) son vaciados de potencialidad y vueltos terreno pasivo para ser intervenido.

La perspectiva centrada en el plano material y mercantilista subestima el 
potencial de los lazos comunitarios y los saberes de las comunidades para acentuar su atención en las carencias materiales. De esta manera, no es extraño observar que las intervenciones desde las políticas estatales en territorios rurales campesinos orientados a mejoras en el hábitat se concentren en trabajar sobre indicadores como la inadecuada calidad de los materiales o los diseños con los que está construida la vivienda, la irregularidad dominial de tierra, etc., invisibilizando de esta manera las potencialidades de la población intervenida por estas políticas. En ese sentido, la erradicación de la vivienda-rancho y su sustitución por una vivienda construida con materiales mampuestos cerámicos y cementicios abre una pregunta: ¿acaso ningún saber constructivo de esta arquitectura vernácula, de este modo de vida campesina, merece considerarse en la resolución de los modelos de vivienda?

\section{Hábitat y desarrollo en el medio rural campesino cordobés}

Aunque las comunidades rurales campesinas cuentan con diversas potencialidades (sin romantizar, es frecuente dar con modos vinculares comunitarios, centrados en valores como la solidaridad y la frugalidad, y también es destacable el acervo de saberes constructivos vernáculos), se perpetúa una perspectiva de acción estatal que establece diferencias, plantea límites y propone acciones tendientes a la 'erradicación' de la pobreza por medio del desarrollo (Escobar, 2007, p. 52), en extensión podemos decir que por añadidura se busca erradicar su expresión materialarquitectónica: el rancho. El sistema de representación que sustenta el discurso acerca del desarrollo, aunque plantea metas de orden humanitario, social, de inclusión y de solidaridad, en la práctica implica nuevas estrategias de control sobre las personas, sus saberes y sus recursos.

Una de las ideas fuerza que se articulan en el discurso del desarrollo, estrechamente vinculada a la de pobreza/carencia, es la de enfermedad. Así, el discurso sanitarista habilita un espacio de intervención estatal por demás justificado:

En Argentina, en 1961 se creó el Programa Nacional del Chagas. En noviembre de 1972, el Programa de Control incorporó un total de 19 Estados provinciales endémicos [(Zaidemberg et al., 2004) en Sesma \& Martínez Coenda, 2019, p. 112] —entre los cuales estaba la provincia de Córdoba - con una estrategia que incluía la desinfección mediante procedimientos químicos de las viviendas rurales. No obstante eso, el Plan de Sustitución de Viviendas Precarias y Erradicación del Mal de Chagas sólo se institucionaliza como política pública en Córdoba en el año 2009 (Sesma \& Martínez Coenda, 2019, p. 112).

A su vez, en la provincia de Córdoba se ejecuta desde el año 2000 una serie de políticas públicas destinadas al medio rural campesino, denominada como Plan 
${ }^{4}$ Las últimas informaciones oficiales fueron provistas por la oficina de prensa de la Gobernación, con fecha de agosto de 2017 (bttp://prensa. cba.gov.ar/gobernacion/ chagas-schiaretti-entrego-la-vivienda-numero2-000-del-plan-de-erradicacion-de-ranchos/), $y$, posteriormente, un periódico local publicó una noticia, en noviembre de 2017, que actualiza la cifra (bttps://www. lavoz.com.ar/politica/ schiaretti-defendio-suplan-social-se-eliminaron2047-viviendas-ranchos).

${ }^{5}$ Incluso miembros del arco politico opositor, discuten el alcance de este plan, mas no ingresan en el planteo mismo de la propuesta (bttp://www.diarioalfil. com.ar/2017/11/08/ controvertida-version-lapobreza-miguel-nicolas/).

${ }^{6}$ En otro trabajo hemos becho referencia a este aspecto, señalando que la tierra, como material predominante en la arquitectura rural, no constituye una amenaza por si sola para la enfermedad de Chagas. Sin embargo, parte de la amenaza la constituyen las inadecuadas resoluciones constructivas de estas viviendas, en donde

$\Longrightarrow$

territarios 43 de Desarrollo del Noroeste Cordobés, que integró desde ese año las acciones destinadas al reemplazo de viviendas. A lo largo del tiempo este plan presentó modificaciones en sus alcances y objetivos, no obstante, se sostuvo el programa de 'erradicación de vivienda-rancho', a través del cual se reemplazaron más de 2000 viviendas. $^{4}$

El programa de erradicación de viviendas-rancho impulsa el mejoramiento de las condiciones del hábitat rural mediante la puesta en marcha de un programa social que promueve la construcción de viviendas nuevas. El programa se basa en el empleo de una tecnología que propone el uso de sistemas constructivos industrializados (mampuesto cerámico y cementicio) impregnada de una lógica urbana en lo que respecta al diseño y los materiales. Esta intervención, que afecta tanto al plano material como al acervo identitario de las comunidades, se encuentra especialmente justificada en el marco de la lucha contra la enfermedad de Chagas-Mazza. Sustentada en la Ley Provincial 9601, que declara la emergencia sanitaria habitacional en la provincia desde el año 2009, se plantea que "[...] para erradicar el mal de Chagas que afecta principalmente a quienes habitan en zonas rurales, es preciso sustituir las viviendas de adobe con techo de jarilla, donde anidaría la vinchuca que es el principal vector de transmisión del Chagas" (Sesma \& Martínez Coenda, 2019, p. 113).
En ese orden de ideas, se expone un elemento recurrente en el discurso y argumentación de los organismos estatales vinculado a cuestiones de salubridad e higiene. De manera subyacente, en la formulación de estas políticas públicas de vivienda en el medio rural cordobés, se considera que la vivienda rural vernácula (aquellas que entran dentro del universo denominado viviendas-rancho) presenta importantes condiciones de insalubridad derivadas de la tecnológica constructiva con las que se resuelven. ${ }^{5}$ Es por este motivo que el programa en cuestión establece como condición la demolición de las viviendas existentes para el acceso al beneficio de las viviendas nuevas. Esta asociación reduce el problema de la proliferación de la vinchuca (vector de la enfermedad) en el espacio construido a los materiales empleados en las técnicas constructivas vernáculas y por su intermedio asocia la enfermedad de Chagas-Mazza con el rancho. ${ }^{6}$

Vale subrayar lo discutible que es la relación lineal, de tipo causa-consecuencia, planteada entre la vivienda de adobe y la enfermedad de Chagas-Mazza, al menos eso se observa en el trabajo de campo realizado en el marco de los proyectos anteriormente señalados. Como cuestión general, es importante anotar que los materiales constructivos de la arquitectura vernácula observada (presentada en la figura 3) no constituyen en sí mismo un factor endémico. Es decir, la vinchuca (vector de la enfermedad) puede anidar 
en cualquier espacio que le brinde cobijo, independientemente de sus materiales (se observan nidos en corrales, cortezas de árboles, bloques cementicios, etc.). Así mismo, de manera particular, de acuerdo con los relatos de algunos habitantes campesinos de las zonas donde se implementa el PSVPEMC, "el mal de Chagas es una enfermedad que actualmente no afecta ( $y$, por ende, no problematiza) a la población rural de la zona" (Sesma \& Martínez Coenda, 2019, p. 113).

Con lo mencionado hasta aquí, es relevante aclarar que no se subestiman los problemas asociados a cuestiones constructivas ni tampoco se subestima la presencia del Estado para la atención de problemáticas habitacionales en el medio rural campesino. Por el contrario, en un estudio presentado junto a colegas arquitectos y arquitectas (Mandrini et al., 2018), desplegamos un análisis tecnológico-político de las definiciones técnicas y de diseño - tanto de la tipología rancho como de las tipologías de viviendas otorgadas por el Estado- en el que no ignoramos la importancia de resolver correctamente terminaciones y encuentros constructivos como medida singularmente relevante para evitar que se aloje la vinchuca. Por otra parte, respecto del rol del Estado, no se pone en cuestionamiento la impostergable responsabilidad que el Estado tiene con los sectores rurales más vulnerables. En todo caso, lo que se propone es revisar el proceso de definición de la idea de progreso, desarrollo o mejora del territorio, para construir mancomunadamente esas definiciones con los actores en el territorio y definir desde allí intervenciones adecuadas orientadas a mejorar la calidad de vida de sus habitantes. En definitiva, lo que se propone es la revisión del sustrato epistémico/gnoseológico a partir del cual se formulan las problemáticas y las soluciones, procurando incorporar otras formas de producción de conocimiento (activamente ignoradas en las trayectorias señaladas) que constituyen las experiencias directas de habitar los territorios.

En ese sentido, sostengo que las definiciones exógenas con que se interviene en el hábitat rural campesino se basan en premisas de orden moderno/colonial que interpretan a las formas de hábitat campesino como expresiones de atraso, del pasado, negando la contemporaneidad de formas de vida que no se inscriben en el discurso del desarrollo. Segato publicó un trabajo (2013), anteriormente citado aquí, en el que desglosa los ejes argumentales que subyacen en la perspectiva de la colonialidad del poder. Quisiera establecer un diálogo con ese trabajo a propósito de las definiciones con que se concibe el hábitat rural campesino.

\section{Argumentos coloniales en el hábitat rural campesino}

Rita Segato se dio a la tarea de reunir y ordenar la serie de proposiciones y formulaciones argumentales que, de manera dispersa, Quijano publicó en sus múltiples muros, discontinuidades en las superficies de techos y cielorrasos. Entonces, la amenaza no se centra en el tipo de material con el que se construya, sino en la calidad de las terminaciones que conforman la construcción. Por tal motivo, el cambio de material con el que está construida la vivienda rural no presenta una solución integral al problema (Mandrini et al., 2017).

territarias 43

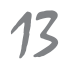


trabajos. En este artículo no desarrollaré por completo esos ejes, que para el caso pueden ser consultados en la obra de Segato $(2013)$, mas me interesa tomar algunos de ellos como herramienta de análisis.

En primer lugar, la autora dice que la perspectiva crítica de colonialidad del poder supone el "reordenamiento de la historia". Se trata del primer elemento, el que funda la perspectiva crítica en su sentido histórico y geopolítico, el cual puede ser presentado en la siguiente idea fuerza: "América inventa Europa" (Segato, 2013 , p. 44). Junto con el momento del "descubrimiento del nuevo mundo" se producen los primeros pasos en el orden global capitalista, dando por iniciada la modernidad/colonialidad. Segato subraya una idea central en el trabajo de Quijano, la cual lo diferencia de los estudios poscoloniales, y es que la emergencia de América (como realidad material y como concepto) es central para el nuevo sistema-mundo, y no periférica. El mundo se reorigina a partir de este descubrimiento.

La formulación señalada da paso a la siguiente argumentación: "América no se incorporó en una ya existente economía mundo capitalista [ya que] una economía mundo capitalista no hubiera tenido lugar sin América" (Quijano \& Wallerstein, 1992, p. 584, en Segato, 2013 , p. 45). Este proceso tiene dos fases: la primera está dada por la novedad que introduce América, gestada bajo el imaginario colonial, por el cual se establece un orden jerárquico entre "Estados y fronteras administrativas" (Segato, 2013, p. 45), afirmada en las ideas de etnicidad y raza, a través de las cuales el sistema-mundo distingue entre blancos, negros, indios, etc., a fin de organizar la explotación moderna/colonial del sistema-mundo capitalista. Los procesos independentistas no modificaron estos patrones de identificación y explotación, que prevalecen en la matriz vincular macro y micropolítica.

De esta manera, la razón del control eurocentrado, va a destacar Segato en su libro, no reside en la propia estructura del capital, sino que reside en la explotación del trabajo: el trabajo no pagado o no asalariado estaba justificado por tratarse de razas inferiores. Así, la idea de raza es piedra basal de toda la erección del sistema-mundo moderno colonial que se estableció, permitiendo que "los blancos", más tarde llamados "europeos", tomaran el lugar de control sobre esta región del mundo y sus habitantes.

Este sistema de categorización y distribución de valores sobre productos y sujetos constituyen modos vinculares que prevalecieron tras la disolución del vínculo formal colonia-metrópoli, reinscribiéndose en actores del territorio. Sobre esto hay mucho trabajo realizado bajo la categoría de 'colonialismo interno' - especialmente trabajan este concepto Silvia Rivera Cusicanqui (2010) y Pablo González Casanova (1963) - que denota un doble juego: por un lado, indica la reproducción de esos órdenes desiguales en la escala socioeconómica local; y, por otro, refiere 
Figura 4. Vivienda del PSVPEMC

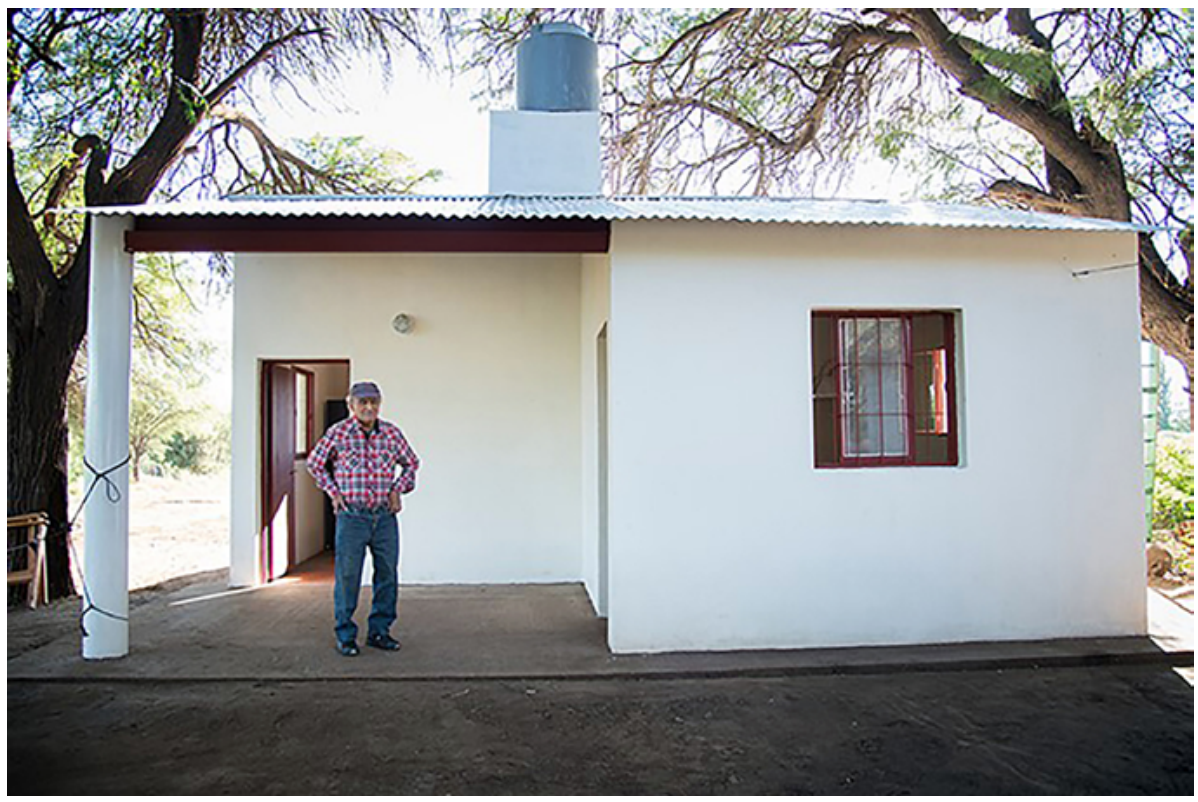

Fuente: diario Día a Día (31 de julio de 2009).

al fenómeno de producción subjetiva por el cual se internalizan y se naturalizan esas diferencias jerarquizadas. Esto puede percibirse en los territorios rurales, donde familias de campesinos históricamente habitantes y trabajadores de las tierras son expulsados, a quienes no se les reconoce los modos de habitar colectivos, donde la lógica de renta especulativa de la tierra se impone, donde a la falta de dispositivos legales para la seguridad en la tenencia de la tierra se le superpone la criminalización y la acción punitiva (CELS, 2017).

Es interesante rastrear en las tipologías de vivienda que el Estado provee (ver figura 4) el imaginario del que están impregnadas. Estas tipologías operan como soporte discursivo capaz de expresar qué tipo de vivienda puede ser considerada como más apta para el medio rural. Así, advertimos cómo está constituido el referente hegemónico de hábitat en el medio rural campesino, el cual se asemeja más a las disposiciones espaciales y de diseño propias del hábitat urbano que al de las disposiciones locales. Esto se manifiesta en las intervenciones estatales que, además de ignorar saberes constructivos vinculados a los materiales de la zona (por el contrario, denostando su uso), replica diseños acordes a las funcionalidades propias de la vida citadina, que no contienen las territarias 43 
${ }^{7}$ En el siguiente video se registra parte de lo que fue un acto de presentación de resultados del Plan de Desarrollo del Noroeste, donde la erradicación de ranchos era una de sus variables. Este acto tiene la cualidad de inscribirse temporalmente en el periodo de lanzamiento de candidatura del por entonces gobernador, José Manuel de la Sota, junto a Sergio Masa para las elecciones presidenciales (bttps://www.youtube. $\mathrm{com} /$ watch $? \mathrm{p}=\mathrm{M} 8 \mathrm{Wp} 0 q$ QGMUIÉfeature $=y o u$ tu.be).

\section{territarios 43}

funcionalidades propias de las prácticas campesinas. Solo por nombrar algunos de estos aspectos, se trata de viviendas con cocinas en el interior de la vivienda (cuando usualmente las cocciones se realizan en la galería o en un fogón aledaño a la vivienda), con habitaciones de grandes ventanas (cuando la práctica habitual es la de mantener el espacio a oscuras), las galerías no tienen las dimensiones suficientes para albergar la funcionalidad que habitualmente tiene (espacio en el que transcurre buena parte del tiempo de encuentro, cocción y también de actividad económica de pequeña escala), el diseño no incluye las vías de comunicación con gallineros, huertas, corrales, etc. La descripción podría continuar, pero me interesa subrayar que, en la práctica intervencionista, se observa una perspectiva arquitectónica urbanista, discursivamente articulada en pares desiguales significativos: tradicional-moderno, atraso-progreso, primitivo-civilizado, siendo la idea de desarrollo, antes señalada, la vía de transición de un estado a otro. Una vez más, ante la pregunta por la posibilidad de integrar saberes constructivos de esta arquitectura vernácula, de este modo de vida campesina, en la resolución de las mejoras en el hábitat, el gesto colonial prevalece.

Con esto traigo al texto otro de los ejes argumentales de la colonialidad del poder, recuperado en el trabajo de Segato: "la colonialidad del saber" $(2013$, p. 50$)$. Este concepto hace referencia al esquema, también jerárquico, que organiza saberes en un escalafón de prestigio, en una relación proporcional con la disolución del espacio de enunciación. Es decir, mientras más alto el prestigio de un saber, más desincorporado. Esta noción se expresa mejor en el concepto de "bybris del punto cero", acuñado por Castro Gómez (2005). Como matriz de producción de conocimiento, el modelo hegemónico erige a un observador privilegiado, que se pretende posicionado por fuera del mundo (punto cero) a fin de aplicar sobre él su mirada analítica, que además se pretende orgánica (de ahí hybris, el pecado de la desmesura en la tradición griega). En definitiva, este modelo epistémico instituye un punto de vista como el punto de vista privilegiado sobre todos los demás, lo cual constituye un aspecto central de la epistemología del colonialismo (Castro Gómez, 2005).

A fin de incorporar — valga el juego de sentidos- en este texto algunos hechos concretos en que se expresan los conceptos que vengo anotando, quiero remitir a un acto $^{7}$ realizado por la Gobernación de la Provincia de Córdoba en el año 2015, donde se llevó a cabo una muestra teatral en la que se presentaron las acciones, los resultados y la perspectiva política con que se desplegaba el Plan de Desarrollo del Noroeste de Córdoba. En ese acto, cito textual, se dijo: "La gente en estos parajes construye con lo que tiene a la mano. Con piedras, palos, ladrillos de adobe, tierra, barro, y construye con sus propias manos, por eso estos parajes son precarios" $(0: 20-0: 30)$. 
En esta expresión se pone de manifiesto una asociación directa entre los saberes constructivos vernáculos y la condición de precariedad, donde el conocimiento local, el saber endógeno, basado en la construcción con los materiales que les brinda su entorno, se presenta en un carácter desventajoso, incluso puede constituir un peligro para la salud. Expresiones de este tipo, que se encuentran frecuentemente en tal clase de comunicaciones oficiales, subalternan las prácticas y los saberes constructivos vernáculos, reduciendo el margen de resolución de las problemáticas locales al restar potencial al acervo de saberes local. De este modo, se asocia un tipo de tecnología (basada en determinados materiales, saberes constructivos y de uso) que a su vez configura un sujeto incompleto, premoderno (en el sentido colonial) y, por lo tanto, susceptible de intervenciones.

Igualmente, siguiendo con otro de los ejes argumentales, mediante estas prácticas se interfiere en la subjetividad de estas comunidades, interviniendo no solo en su medio construido, sino también en su memoria histórica, sus saberes, su cosmología en torno al hábitat, que, tras la intervención se encuentran menoscabadas o, de hecho, impedidas de objetivar (Segato, 2013, p. 51). Existe un cúmulo de saberes que expresan valores, sentidos estéticos, formas de habitar (articuladas en funciones residenciales, productivas y de sociabilización) que son menospreciadas, desautorizadas. Ejemplo de esta forma de infamar el universo de saberes constructivos rurales, campesinos (con todo lo que implican) puede identificarse en otro de los fragmentos del acto público mencionado, donde se invisibiliza por completo las formas de habitar que de hecho existen: "Tenemos caminos, tenemos agua, tenemos luz, tenemos granja, tenemos autoabastecimiento, tenemos emprendimientos familiares. Ahora, ahora es tiempo de saber dónde van a vivir" (0:02-0:16).

Los saberes constructivos y los modos de habitar rurales campesinos constituyen la expresión de un campo de conocimiento históricamente producido, comunicado de generación en generación por medio de la recuperación de la memoria oral, fundado en el conocimiento profundo del territorio. Las perspectivas con que el Estado se aproxima e interviene responden a la perspectiva colonial que produce repetidas y renovadas formas de exclusión: en la escala micropolítica, se puede decir que actúa desconociendo saberes y prácticas de la comunidad, decidiendo sobre su patrimonio, mancillando la parte de su identidad que se expresa en su arquitectura, imposibilitando la continuidad de sus prácticas productivas. En un nivel macropolítico, podemos decir que no se abordan los problemas de hábitat de las comunidades rurales campesinas desfavorecidas desde las causas que generan su situación de exclusión; en ese sentido, es necesario avanzar en el reconocimiento de sus formas de habitar la tierra, generando territarias 43 17 
seguridad en la tenencia, colaborando en la mejora de las condiciones edilicias (lo cual puede implicar el reemplazo de vivienda, si las familias así lo desean, pero también puede implicar la mejora en las terminaciones de los espacios construidos existentes), garantizando el acceso al agua y a la energía en cantidades necesarias (que permitan el desarrollo de sus actividades productivas, residenciales y de sociabilidad), fortaleciendo su soberanía alimenticia, restringiendo el uso de agroquímicos, fomentando espacios para el comercio justo de sus producciones agrícolas, garantizando caminos y medios de transporte, entre otras medidas.

Esto da paso a los dos últimos argumentos que me interesa recuperar del planteo de Segato a fin de enriquecer el debate sobre el hábitat rural campesino aquí propuesto: la "razón eurocéntrica instrumental y tecnocrática", por un lado, y un "nuevo imaginario anticapitalista", por otro. En rigor, no se trata de categorías separadas, ya que ambas se expresan en el territorio a través de la relación con la naturaleza, mediada por el trabajo.

Dicho de manera sucinta, el proyecto de la modernidad/colonialidad incluye un tipo de racionalidad, de tipo instrumental y tecnocrática, que se expresa en la colonialidad de la naturaleza. La operación racional a través de la cual se escinde la vida humana de las condiciones de la naturaleza permite construir una relación de exterioridad con esta última, favoreciendo así las condiciones para la apropiación o explotación de sus riquezas (Segato, 2013, p. 55). Esta condición está en la base del modelo de acumulación, un modelo de acumulación por desposesión va a decir David Harvey, señalando la operación vincular en la que se funda el modelo centrado en la materialidad y en la pretendida posibilidad de crecimiento ilimitado. Este argumento colonial enlaza con la discusión en torno al desarrollo que fue presentada anteriormente, por lo cual no anotaré más que lo siguiente: revisar el modelo de desarrollo esencialmente implica revisar el modelo capitalista, que se funda en el marco de la modernidad/ colonialidad, cuyos fundamentos no se detienen siquiera ante la muerte de comunidades vulnerables. En tal orden de ideas, categorías como "zona de sacrificio", acuñada desde las luchas ambientalistas, procuran mostrar los efectos siniestros que contiene y perpetúa este modelo. Particularmente esta noción permite reconocer sus expresiones territoriales (Vanoli, 2020) como un ejercicio de disputa por el habitar.

Las luchas ambientalistas, ecofeministas, indígenas, presentan como factor común la disputa por la hegemonía del modelo capitalista, pugnan por un 'nuevo imaginario anticapitalista' y, en ese sentido, los movimientos campesinos también se inscriben en esa lucha. Anteriormente señalé que una de las operaciones centrales para la justificación de las intervenciones está dada por el doble movimiento que supone la identificación del campesinado bajo la categoría de 'pobres' o 'carentes' 
(tal como apunté, esencialmente articulada desde las condiciones materiales y económicas de existencia): por un lado, se vacía de potencia a estos sujetos, invisibilizando sus luchas y saberes; y, por otro lado, son catalogados como terreno pasivo para ser intervenido. En ese marco se vuelve posible preguntar iy ahora dónde van a vivir?, como lo hicieran en aquel acto gubernamental, ignorando por completo saberes y prácticas existentes. Desde esa activa invisibilización se vuelve posible definir como 'acceso universal a la energía', por dar algunos ejemplos concretos, la escasa disposición de pequeños paneles solares para carga de celulares; se vuelve posible posponer infinitamente discusiones acerca de la seguridad jurídica en la tenencia o reducir la lucha de poblaciones fumigadas a injerencias propias de organizaciones vecinales, entre 'privados'.

Sin embargo, la gesta histórica de supervivencia campesina ha construido saberes que podrían constituir lo que Quijano ha nombrado como nuevo imaginario anticapitalista, definiéndose desde la economía popular, social y solidaria, desplegando redes de producción y comercio orientadas a satisfacer sus necesidades que no toman de la naturaleza más de lo que necesitan. De este modo, la expresión territorial del hábitat rural campesino incluye su funcionalidad productiva (articulada con la residencial y la de organización social, como mencioné anteriormente), lo cual se expresa en el territorio más allá de los espacios construidos, zonificado por prácticas diversas (por ejemplo, huerta, chiquero, corral, depósito de herramientas, espacio de secado de frutos de monte y un largo etcétera, todo depende de cuál sea su producción), cuyas definiciones incluyen las disposiciones de sombra a lo largo del día, la posibilidad de los animales para acceder a pasturas, el modo en que en el terreno escurre el agua de lluvia, el acceso a caminos, etc.

\section{Conclusiones}

Hay algo que opera en las políticas habitacionales orientadas a comunidades rurales campesinas que podría sintetizarse de este modo: se puede dudar del grado de desarrollo de una región, sin dudar del discurso del desarrollo en sí. Este artículo invita a revisar los alcances de aquello que se considera 'desarrollo', considerando que se trata de un dispositivo vincular colonialista, que, en tanto no plantea un diálogo de saberes y un fortalecimiento de las prácticas campesinas, simplemente hace de la justicia social un discurso efímero.

Boaventura de Sousa Santos dice, en Una epistemología del Sur (2009), que no habrá justicia social global sin justicia epistémica global y esta idea fuerza hace mella en el trabajo aquí desplegado. Existen formas de habitar que no se ajustan a la perspectiva dominante del mundo moderno/colonial. El Estado, como garante del acceso al hábitat digno, se encuentra en la tarea de desmantelar aquellos dispositivos coloniales con los cuales aborda territarias 43

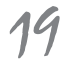


estos territorios, y con ellos a las propias subjetividades de sus habitantes.

En ese sentido, consideramos que las políticas orientadas a la erradicación de formas constructivas locales y su reemplazo por formas exógenas no solo pueden no ser una solución, sino que además pueden constituir nuevos problemas. Por medio de las acciones de erradicación se socaban formas de conocimiento, cuyo soporte discursivo está dado por un tipo de arquitectura vernácula (figura 5), la cual entrelaza expresiones materiales con la propia identidad. El diálogo entre saberes constructivos (locales y exógenos) y la atención sobre las luchas en territorio que persiguen formas dignas de vida abre un espacio de gran potencial que pudiera

Figura 5. Posible zonificación de vivienda rural/campesina

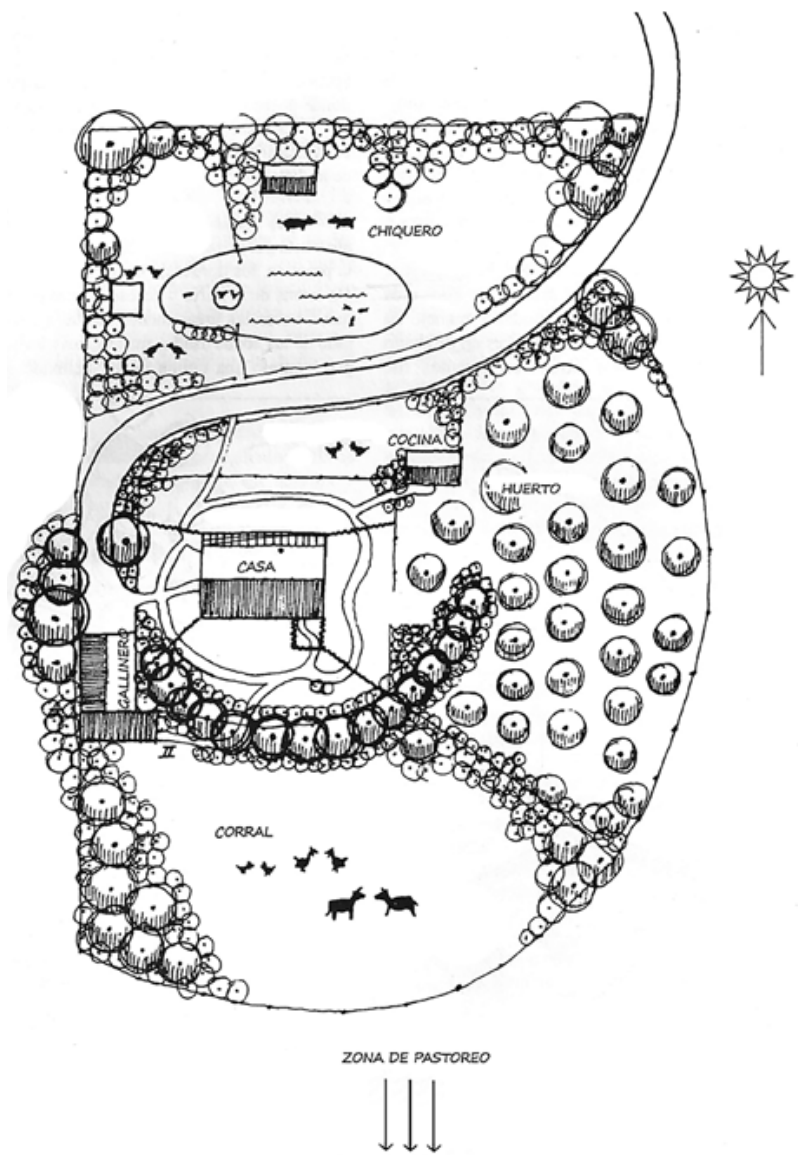

Fuente: imagen extraída de Granja Escuela La Ilusión (2013) reeditada por la autora. 
hacer más adecuadas las intervenciones estatales.

\section{Referencias}

Castro Gómez, S. (2005). La hybris del punto cero. Ciencia, raza e Ilustración en la Nueva Granada (1750-1816). Centro Editorial Javeriano-Instituto Pensar.

CELS. (2017). Hábitat digno: diez propuestas de politicas públicas ( $1^{\mathrm{a}} \mathrm{ed}$.).

De Sousa Santos, B. (2009). Una epistemología del Sur: la reivindicación del conocimiento y la emancipación social. Siglo XXI-Clacso.

De Sousa Santos, B. (2017). Justicia entre saberes: epistemologías del Sur contra el epistemicidio. Ediciones Morata.

Escobar, A. (2007). La invención del tercer mundo. Construcción y deconstrucción del desarrollo. Fundación Editorial El perro y la rana.

FAO. (2018). Panorama de la pobreza rural en América Latina y el Caribe 2018.

Foucault, M. (1999). La arqueologia del saber. Siglo XXI Editores S.A.

GIEH. (2017). Archivo fotográfico del trabajo de campo realizado en el departamento Pocho de la provincia de Córdoba (Argentina).

GIEH. (2018). Archivo fotográfico del trabajo de campo realizado en el departamento Tulumba de la provincia de Córdoba (Argentina).

González Casanova, P. (1963). Sociedad plural, colonialismo interno y desarrollo.
América Latina: Revista del Centro Latinoamericano de Investigaciones en Ciencias Sociales, VI(3).

Grosfoguel, R. (2006). La descolonización de la economía política y los estudios postcoloniales. Transmodernidad, pensamiento fronterizo y colonialidad global. Tabula Rasa, (4), 17-48.

Leguizamón Sarmiento, J. P. (2012). Ecosofía del habitar una propuesta de vivienda (Tesis de Arquitectura, Pontificia Universidad Javeriana, Facultad de Arquitectura y Diseño).

Mandrini, M. R., Cejas, N., \& Bazán, A. (2017). Erradicación de ranchos ¿̨erradicación de saberes? Reflexiones sobre la región noroeste de la provincia de Córdoba, Argentina. Anales del IAA, 48(1), 83-94. http://www.iaa.fadu. uba.ar/ojs/index.php/anales/article/ view $/ 265 / 453$

Mandrini, M. R., Cejas, N., Rolón, G., \& Di Bernardo, A. (2018). Desnaturalizando fundamentos coloniales. Revisión de la política pública para el hábitat rural en la región noroeste de Córdoba, Argentina. Área, (24), 89-103.

Múnera, M. C., \& Sánchez Mazo, L. (2012). Construcción social de hábitat: reflexiones sobre políticas de vivienda en Colombia. En Politicas de empleo y vivienda en Sudamérica (pp. 75-93). Instituto de la Ciudad-Flacso Ecuador-Clacso.

Quijano, A. (3-6 de diciembre de 1985). Las ideas son cárceles de larga duración, pero no es indispensable que permanezcamos territarias 43 21 
todo el tiempo en esas cárceles. Sesión de cierre del Seminario Clacso, XIII Asamblea General Ordinaria, Montevideo.

Quijano, A. (1990). Notas sobre los problemas de investigación social en América Latina. Revista de Sociologia, 6(7).

Quijano, A., \& Wallerstein, I. (1992). La americanidad como concepto, o América en el moderno sistema mundial. Revista Internacional de Ciencias Sociales. América: 1492-1992, (4), 584-591.

Rivera Cusicanqui, S. (2010). Violencias (re)encubiertas en Bolivia. Editorial Piedra Rota.

Segato, R. (marzo-abril, 2007). El color de la cárcel en América Latina. Apuntes sobre la colonialidad de la justicia en un continente en desconstrucción. Nueva Sociedad, (208).

Segato, R. (2013). La crítica de la colonialidad en ocho ensayos y una antropologia por demanda. Prometeo Libros.

Sesma, M. I., \& Martínez Coenda, V. (2019). La regulación del hábitat rural en Córdoba. ReviISE - Revista de Ciencias Sociales y Humanas, 14(14), 109-120. http://www.ojs.unsj.edu.ar/ index.php/reviise/article/view/333

Vanoli, F. (2020). Espacio y dominación: zonas de sacrificio ambiental y subjetividades disidentes (Tesis doctoral, Centro de Estudios Avanzados, Universidad Nacional de Córdoba).

\section{Fuentes web consultadas}

(31 de julio de 2009). Día a Día. https://empleoyfamilia.cba.gov.ar/ noc-mas-familias-cumplieron-susueno-de-tener-una-vivienda-digna/

Granja Escuela La Ilusión. (2013). Zonificación 5. https://granjaescuelalailusion.wordpress. com/2013/05/11/permacultura-iiiplanificacion-eficiente-de-la-energia-yanalisis-de-la-red-de-funcionamiento/ zonificacion-5/

http://prensa.cba.gov.ar/gobernacion/ chagas-schiaretti-entrego-la-viviendanumero-2-000-del-plan-de-erradicacion-de-ranchos/

http://www.diaadia.com.ar/content/ empieza-el-desalojo-de-la-vinchucaadios-los-ranchos- 5

h t t p : // w w w. diarioalfil.com . $\operatorname{ar} / 2017 / 11 / 08 /$ controvertida-version-la-pobreza-miguel-nicolas/

https://www.lavoz.com.ar/politica/ schiaretti-defendio-su-plan-social-seeliminaron-2047-viviendas-ranchos https://www.youtube.com/watch?v=M 8Wp0qQGMUI\&feature $=$ youtu.be 